\title{
Absence of Ligands Bound to Glycoprotein IIB-IIIA on the Exposed Surface of a Thrombus May Limit Thrombus Growth in Flowing Blood
}

\author{
Harry F. G. Heynen, ${ }^{\star}$ Miguel Lozano Molero, ${ }^{\ddagger}$ Philip G. de Groot, ${ }^{\ddagger}$ H. Karel Nieuwenhuis, ${ }^{\ddagger}$ and Jan J. Sixma ${ }^{\ddagger}$ \\ ${ }^{*}$ Department of Cell Biology, University of Utrecht, Utrecht, The Netherlands; and ${ }^{\ddagger}$ Department of Haematology, \\ University Hospital, NL-3508 GA Utrecht, The Netherlands
}

\begin{abstract}
We examined the distribution of glycoprotein IIb-IIIa (GPIIb-IIIa) and its ligands fibrinogen and von Willebrand factor (vWf) on platelets which had adhered under flow conditions. Immunoelectron microscopy was performed on whole mounts and frozen thin sections of adhering platelets. GPIIb-IIIa was homogeneously distributed on dendritic platelets and on interplatelet membranes of formed thrombi. Fibrinogen and vWf were predominantly associated with interplatelet membranes and membranes facing the substrate. On whole mounts, vWf appeared in clumps and linear arrays, representing the tangled or extended forms of the multimeric molecule. From semiquantitative analysis, it appeared that fibrinogen and vWf were, respectively, nine- and fourfold higher on interplatelet membranes than on surface membranes facing the blood stream, while GPIIb-IIIa was evenly distributed over all platelet plasma membranes. Ligand-induced binding sites (LIBS) of GPIIbIIIa, as measured with conformation specific monoclonal antibodies RUU 2.41 and LIBS-1, were present on the surface of adhered platelets and thrombi. A redistribution of LIBS-positive forms of GPIIb-IIIa towards interplatelet membranes was not observed. Our data support the hypothesis that, under flow conditions, ligands have first bound to activated GPIIb-IIIa but this binding is reversed on the upper surface of adhering platelets. This relative absence of ligands on the exposed surface of thrombi may play a role in limiting their size. (J. Clin. Invest. 1994. 94:1098-1112.) Key words: platelet adhesion • electron microscopy • GPIlbIIIa - fibrinogen • von Willebrand factor
\end{abstract}

\section{Introduction}

At sites of vascular injury, platelets undergo a complex series of biochemical and morphological events, essential for normal hemostasis. Adhesion of platelets to the damaged vessel wall is the first step in this series of events (1-3). Platelet activation and aggregation occur after adhesion to the exposed subendothelium (4). All these processes are mediated by specific mem-

Dr. M. Lozano Molero's present address is Hospital Clinico Provincial, Servicio de Hemoterapia y Hemostasis, 08036 Barcelona, Spain. Address correspondence to Dr. J. J. Sixma, Department of Haematology, GO3.647, University Hospital Utrecht, P.O. Box 85500, NL-3508 GA Utrecht, The Netherlands.

Received for publication 10 November 1992 and in revised form 19 April 1994

J. Clin. Invest.

(c) The American Society for Clinical Investigation, Inc.

0021-9738/94/09/1098/15 $\$ 2.00$

Volume 94, September 1994, 1098-1112 brane glycoproteins on the platelet surface and their ligands. Glycoprotein Ib and vWf are particularly involved in the initial attachment of platelets to the vessel wall $(2,5,6)$, and it has become evident that GPIIb-IIIa also participates in platelet adhesion (7). Plasma vWf does not bind to nonactivated circulating platelets, but adhesion of platelets to subendothelium strongly depends on vWf bound to it (5). Besides playing a role in platelet adhesion, $v W f$ is also involved in platelet-platelet interaction, particularly at high shear rate through interaction with GPIIb-IIIa $(8,9)$. Platelet membrane GPIIb-IIIa is the major receptor for fibrinogen, vWf, fibronectin, and vitronectin and is essential for platelet aggregation $(10,11)$. In response to physiological agonists such as ADP or thrombin, platelets bind circulating fibrinogen via exposed GPIIb-IIIa on the membrane of activated platelets (12-15). The distribution of platelet membrane GPIIb-IIIa on resting and stimulated platelets as well as on platelets spread on a surface has been the subject of several studies using a variety of approaches (16-22). WencelDrake (16) reported cycling of GPIIb-IIIa between $\alpha$-granules and the plasma membrane, when platelets were incubated with specific monoclonal antibodies. Local redistribution events in terms of GPIIb-IIIa clustering were described after agonist stimulation of platelets in suspension (17). Agonist stimulation in suspension resulted in accumulation of fibrinogen-gold in channels of the open canalicular system (OCS) ${ }^{1}(19)$. Translocation of GPIIb-IIIa towards platelet centers and accumulation in channels of the OCS was observed when surface-spread platelets were incubated with fibrinogen-gold (20-23). Such a redistribution of GPIIb-IIIa, however, was not found when platelets were fixed before immunolabeling (24). These studies on receptor distribution using activation by surfaces or agonists, followed by ligand binding, were all performed under static conditions. Moreover, several of these studies were performed on platelets that were fully spread on nonphysiological surfaces. Perfusion experiments in our laboratory have shown that the ability of platelets to form either a monolayer or aggregates strongly depends on the surface and shear rate (25). Redistribution of GPIIb-IIIa after adhesion may be an important condition for formation of platelet aggregates. In addition, exposure of internal receptor pools and/or microenvironmental changes of GPIIb-IIIa upon platelet activation may result in secondary platelet responses $(26-28)$.

Here we study the receptor distribution and the association of ligands under flow conditions. Immunoelectron microscopy was performed on whole mounts and frozen thin sections of platelets that had adhered to type I collagen and matrices of human endothelial cells and fibroblasts after perfusion with whole blood. The surface expression as well as interplatelet

1. Abbreviations used in this paper: LIBS, ligand-induced binding site; OCS, open canalicular system; PAG5, PAG10, and PAG15, protein A conjugated to 5,10 , and $15 \mathrm{~nm}$ gold particles, respectively. 
Table I. Specificity and Immunocytochemical Properties of Anti-GPIIb-IIIa Antibodies Used in This Study

\begin{tabular}{llc}
\hline \multicolumn{1}{c}{ Antibody* } & \multicolumn{1}{c}{ Specificity } & $\begin{array}{c}\text { Surface } \\
\text { labeling }\end{array}$ \\
\hline mAb LIBS-1 & $\begin{array}{c}\text { GPIIIa: ligand-induced binding } \\
\text { site on activated platelets }\end{array}$ & + \\
mAb RUU SP 2.41 & $\begin{array}{c}\text { GPIIb-IIIa: ligand-induced binding } \\
\text { site on activated platelets }\end{array}$ & + \\
Rabbit polyclonal & $\begin{array}{c}\text { GPIIb-IIIa: resting and stimulated } \\
\text { platelets anti-GPIIb-IIIa }\end{array}$ & + \\
Rabbit polyclonal & $\begin{array}{c}\text { GPIIb: resting and stimulated } \\
\text { platelets anti-GPIIb }\end{array}$ & + \\
mAb C17 & \begin{tabular}{c} 
GPIIIa: resting and stimulated \\
\hline
\end{tabular} & + \\
\hline
\end{tabular}

The immunolabeling was performed on frozen thin sections and after preembedding staining. ${ }^{*}$ For references see Methods.

localization and polarity were studied after preembedding and postembedding labeling and ultra-thin cryosectioning of adhering platelets. GPIIb-IIIa was distributed homogeneously on membranes of adhering dendritic platelets and on platelets in thrombi formed during perfusion. In contrast, ligands associated with GPIIb-IIIa were concentrated between platelets at the sites of interplatelet contact, with a conspicuous absence on the exposed upper surface of the platelets. Using monoclonal antibodies that recognize ligand-occupied forms of GPIIb-IIIa (LIBS1 and RUU SP 2.41), we found no preferential distribution of ligand-induced binding site (LIBS) positive forms of GPIIbIIIa at interplatelet membranes.

\section{Methods}

Materials. Low molecular weight heparin $\left(\right.$ Fragmin $\left.^{\mathrm{R}}\right)$ was obtained from KabiGen AB (Stockholm, Sweden). Melamine (1\% wt/vol solution of hexamethylol-melamine-ether and $0.3 \%$ para-toluene sulphonic acid) was obtained from Agar Scientific (Stansted, UK). Desulphatohirudin was a gift of Dr. R. B. Wallis (Ciba-Geigy Pharmaceuticals, Horsham, UK).

Antibodies. A list of the used anti-GPIIb-IIIa antibodies with their properties is given in Table I. Rabbit polyclonal anti-GPIIb was from our own department. It stained only the GPIIb band in Western blots of SDS-PAGE of whole platelets and it showed no staining with platelets of a patient with Glanzmann thrombasthenia. Rabbit polyclonal antiGPIIb-IIIa and polyclonal anti-P-selectin (GMP140) were a gift from Dr. M. C. Berndt (Baker Medical Research Institute, Prahran, Victoria, Australia) and were described previously (29). Monoclonal antibody C17, directed to GPIIIa was a kind gift from Dr. A. von dem Borne (CLB Biotechnology, Amsterdam, The Netherlands) (30). To detect conformational changes in the GPIIb-IIIa complex that occur during platelet adhesion and aggregation under flow two activation-dependent monoclonal antibodies were used. mAb RUU SP 2.41 was developed in our own department according to standard procedures as described previously (31). Briefly, mice were immunized with paraformaldehydefixed thrombin-activated platelets. The IgG-containing fraction was obtained by affinity chromatography on a protein A-agarose column. The antibody (IgG1) does not react with resting platelets and binds to ADP or thrombin-activated platelets in the presence of fibrinogen or fibronectin as studied with FACS ${ }^{\circledR}$ analysis. mAb 2.41 binds to 21,000 sites on thrombin-stimulated platelets. The antibody does not react with activated Glanzmann platelets, suggesting that 2.41 reacts with an epitope on GPIIb-IIIa, an epitope which is exposed on the surface of the platelet after a conformational change in the complex has occurred through the binding of fibrinogen (Metzelaar, M., H. K. Nieuwenhuis, and J. J.
Sixma, unpublished data). LIBS-1 monoclonal antibody (IgG1) was a generous gift from Dr. M. Ginsberg (Scripps Research Institute, La Jolla, CA) and is also a conformation-specific antibody. It recognizes an epitope in GPIIIa after interaction of the complex with a ligand (ligand-induced binding site), and the binding of the antibody is upregulated by fibrinogen and other RGD-containing ligands to 15,000-21,000 sites $(32,33)$. Polyclonal anti-human vWf antiserum was raised in rabbits as described previously (34). The IgG fraction was adsorbed on a protein A-Sepharose column and was affinity purified. Rabbit polyclonal anti-human fibrinogen and mouse antithrombospondin ascites were purchased from Dakopatts (Glostrup, Denmark). Polyclonal antifibronectin antibody was purchased from Cappel Organon Teknika Corporation (West Chester, PA). Polyclonal antivitronectin antibody was a gift from Dr. K. Preissner (Max-Planck Gesellschaft, Bad Nauheim, Giessen, Germany). Secondary antibodies, swine anti-rabbit IgG and rabbit anti-mouse IgG, were purchased from Sigma Immunochemicals (St. Louis, MO).

Cell culture and matrices. Melamine-coated coverslips were used for cell culture and were prepared as described by Westphal et al. (35). Briefly, glass coverslips ( $18 \times 18 \mathrm{~mm}$; Menzelgläser, Braunschweig, Germany) were coated with melamine by dipping in a $1 \%$ melamine solution, containing $0.3 \%$ para-toluene sulphonic acid, dissolved in analytical grade ethanol. The coverslips were then withdrawn by hand and directly flamed for polymerization and sterilization. Sterile melamine coverslips were precoated with a $1 \%$ gelatin solution in $0.1 \mathrm{M}$ PBS, $\mathrm{pH}$ 7.40. Human umbilical vein endothelial cells were cultured on gelatincoated melamine coverslips as described for untreated coverslips (5). Fibroblasts derived from human fetal lung tissue or human skin were cultured in essentially the same way, except that $20 \%$ pooled human serum was replaced by $10 \%$ fetal calf serum. After the cells had grown to confluence, endothelial cell matrices and fibroblast matrices were harvested by incubating the cells for 10 min with $0.1 \mathrm{M} \mathrm{NH}_{4} \mathrm{OH}$ at room temperature. After extensive washing with $10 \mathrm{mM}$ Hepes in 0.15 $\mathrm{M} \mathrm{NaCl}$, the matrices were stored at $4^{\circ} \mathrm{C}$ until used for perfusion studies. As a rule, the matrices were used within $48 \mathrm{~h}$ after harvesting. Type I collagen, obtained from calf skin (Sigma Immunochemicals), was dissolved in $50 \mathrm{mM}$ acetic acid. A final concentration of $30 \mu \mathrm{g} / \mathrm{cm}^{2}$ was sprayed on the melamine-coated coverslips using a retouching airbrush connected to a nitrogen cylinder operating at a pressure of one atmosphere (36).

Blood. Blood from healthy donors was anticoagulated with $1 / 10$ volume of $200 \mathrm{U} / \mathrm{ml} \mathrm{low} \mathrm{molecular} \mathrm{weight} \mathrm{heparin} \mathrm{(Fragmin}{ }^{\oplus}$; KabiGen $\mathrm{AB}$ ) or $50 \mathrm{U} / \mathrm{ml}$ unfractionated heparin in PBS (Organon, Oss, The Netherlands). When indicated, $20 \mathrm{U} / \mathrm{ml}$ desulphatohirudin was added to the perfusate just before perfusion. Platelet counts and hematocrit were determined with a Sysmex NE 8000 (Charles Goffin, Ijsselstein, The Netherlands). Control platelets were obtained from platelet-rich plasma by $10 \mathrm{~min}$ of centrifugation at $200 \mathrm{~g}$ at $20^{\circ} \mathrm{C}$. The platelets were directly fixed in $2 \%$ paraformaldehyde and $0.2 \%$ glutaraldehyde in 0.1 $M$ sodium phosphate buffer, $\mathrm{pH} 7.40$.

Perfusion. Perfusions were carried out with whole blood at $37^{\circ} \mathrm{C}$ using the parallel plate perfusion chamber described previously (37). Blood flow was laminar at the region of the coverslips. Wall shear rates were calculated from the formula used by Muggli et al. (38). Whole blood perfusions were carried out for $5 \mathrm{~min}$ at a shear rate of $300 / \mathrm{s}$ or $1600 / \mathrm{s}$. Directly after perfusion, the chamber containing the perfused coverslips was thoroughly rinsed with $10 \mathrm{mM}$ Hepes in $0.15 \mathrm{M} \mathrm{NaCl}$ ( $\mathrm{pH} 7.35$ ). The coverslips were fixed in a mixture of $2 \%$ paraformaldehyde and $0.2 \%$ glutaraldehyde in $0.1 \mathrm{M}$ phosphate buffer ( $\mathrm{pH}$ 7.4). For en face analysis of total platelet coverage, samples of the whole mount preparations were mounted on glass slides, stained with May-Grünwald Giemsa (Merck, Darmstadt, Germany), and evaluated using light microscopy and image analyzing (AMS 40-10 Image-Analyser; Analytical Measuring Systems, Shirehill, Essex, UK) (5).

Electron microscopy. Fixed coverslips were rinsed three times with PBS containing $0.15 \mathrm{M}$ glycine, $\mathrm{pH} 7.40$, followed by incubation with PBS containing $0.1 \%$ BSA. Samples were either prepared for whole mount evaluation or for ultra-thin cryosectioning. In some instances, coverslips were first incubated with antibodies and protein A-gold and 
then prepared for ultra-thin cryosectioning followed by postimmunostaining. Immunolabeling on whole mounts was performed on $50-\mu 1$ drops on parafilm. The coverslips with adhered platelets facing downwards were transferred to the antibody drops, incubated for $60 \mathrm{~min}$, and rinsed with PBS plus $0.1 \%$ BSA. The antibodies were visualized using protein A-gold markers prepared according to the method of Slot et al. (39). Control incubations were carried out on nonperfused matrices using polyclonal antifibrinogen and anti-vWf antibody in combination with protein $\mathrm{A}$-gold or alternatively with protein $\mathrm{A}$-gold alone to check for the presence of ligand or IgG in the matrices before perfusion. For whole mount evaluation, the coverslips were fixed in $1 \%$ glutaraldehyde in $0.1 \mathrm{M}$ phosphate buffer, and were rinsed and postfixed in $1 \% \mathrm{OsO}_{4}$ for $30 \mathrm{~min}$. Samples were dehydrated through a graded series of ethanol to absolute ethanol and finally dried in a critical point device (CPD 010; Balzers Aktiengesellschaft, Liechtenstein). The dried samples were stabilized with carbon evaporation and carefully cut into small squares with a razor blade. Coverslips were placed cell-side-up on a drop of $0.4 \%$ hydrofluoric acid in a small Petri dish $(30 \mathrm{~mm})$, and within $2-5$ min the melamine foil separated from the glass coverslip. The hydrofluoric acid solution was replaced by distilled water, and the foils were mounted on electron microscopy grids. The whole mount preparations were examined in a JEOL $1200 \mathrm{EX}$ electron microscope, at $120 \mathrm{kV}$. A $12^{\circ}$ tilting angle was used to produce stereo-paired electron micrographs.

Ultra-thin cryosectioning. For ultra-thin cryosectioning, fixed coverslips were rinsed three times with PBS, followed by a 10-min incubation in PBS containing $5 \%$ gelatin at $37^{\circ} \mathrm{C}$. The backside of the coverslips was dried, and enough gelatin was removed from the upper surface to leave a thin layer. The coverslips were then placed on ice to solidify the gelatin layer. Removal of the melamine foil with adhered platelets from the glass coverslips was now carried out with the aid of $0.8 \%$ hydrofluoric acid, at $4^{\circ} \mathrm{C}$. Because of the gelatin layer, a higher hydrofluoric acid concentration and a longer separation time were needed. The separation of the foil from the glass coverslip took generally 15-20 min. The hydrofluoric acid solution was replaced by distilled water, and the foil was picked up with a pair of tweezers and transferred to a $10 \%$ gelatin in PBS at $37^{\circ} \mathrm{C}$. The reason for this was to maintain the foils with adhering platelets in a gelatin environment. The foils with adhering platelets were centrifuged carefully, and the gelatin was solidified at $4^{\circ} \mathrm{C}$. Small gelatin blocks were then cut from the pellet, immersed in $2.3 \mathrm{M}$ sucrose at $4^{\circ} \mathrm{C}$, and frozen in liquid nitrogen. Ultrathin cryosectioning was performed on a Reichert FC 4E and Ultracut $S$ microtome (Leica Aktiengesellschaft, Reichert Division, Vienna, Austria) and immunogold labeling was performed according to the method of Tokuyasu as adapted by Slot et al. (40). Specificity of the immunolabeling was verified using a control antibody directed against amylase and protein A-gold or protein A-gold alone. In the case of monoclonal antibody RUU SP 2.41 and LIBS-1, we used rabbit anti-mouse IgG as an intermediate step. Immunolabeling was also performed on ultra-thin cryosections of freshly fixed platelets, obtained from platelet-rich plasma samples before perfusion, or from platelets, obtained from blood directly collected into fixative. The relative distribution of GPIIb-IIIa, vWf, and fibrinogen on platelets that adhered to type I collagen was analyzed in comparative single and double labeling experiments using different gold markers. Semiquantitative analysis of immunogold labeling was performed on electron micrographs that were randomly selected at low magnification. Platelet membranes were divided into upper thrombus membranes, interplatelet membranes, and platelet surface interfaces. Gold particles were attributed to the upper surface when no adjacent membranes were present. A lattice was used on the same electron micrographs to estimate the membrane surface area. Label densities were obtained by dividing the relative number of gold particles by the relative number of membrane intersections. The label was expressed as a percentage of the total label.

\section{Results}

The use of melamine-coated substrates gave us the unique possibility to evaluate platelet coverage at the light microscopy level
Table II. Percentage of Surface Coverage after Whole Blood Perfusion over Endothelial Cell Matrix (ECM), Fibroblast Matrix (FM), and Type I Collagen

\begin{tabular}{lcr}
\hline \multicolumn{1}{c}{ Surface } & Glass & Melamine-coated \\
\hline FM & $79.0 \pm 2.6$ & $78.1 \pm 6.2$ \\
ECM & $11.8 \pm 0.3$ & $13.3 \pm 3.9$ \\
Collagen type I & $14.7 \pm 1.1$ & $14.6 \pm 1.2$ \\
Melamine alone & & $1.0 \pm 0.8$ \\
\hline
\end{tabular}

Comparison of uncoated coverslips versus melamine-coated coverslips. Surface coverage was evaluated as mentioned in Methods.

and at the same time to study the surface distribution of membrane glycoproteins and ligands on whole mount preparations at the electron microscopy level. Moreover, the melamine foils were very suitable to study interplatelet and platelet substrate interactions on frozen thin sections.

\section{Whole mount evaluation}

General observations. No platelet adhesion was observed when melamine foils, blocked with $1 \%$ human serum albumin, were exposed to flowing blood. Platelet adhesion to melamine foils coated with collagen type I or with the matrix of endothelial cells or fibroblasts was similar to adhesion to the same substrate directly coated to glass (Table II). Platelet adhesion after $5 \mathrm{~min}$ of perfusion over endothelial cell matrix is illustrated in Fig. 1 $a$. Dendritic and more extensively spread platelets had attached to the endothelial cell matrix. Fig. $1 b$ shows an example at higher magnification after immunolabeling of GPIIb. Membrane-bound gold particles are only visualized on the electron lucent margins of spread platelets and occasionally on pseudopodes. Analysis of gold particles, however, was not possible over whole cell bodies and platelet aggregates. On cross-sections, however, the label distribution could easily be analyzed over dendritic platelets. Therefore, semiquantitative analysis of receptor distribution was solely carried out on cross-sections.

Immunolabeling of fibrinogen and $v W f$. After perfusion with low molecular weight heparin anticoagulated whole blood and immunolabeling with a polyclonal antifibrinogen antibody followed by protein $\mathrm{A}$-gold, local high labeling densities were observed on the whole mounts, apparently representing the initial formation of fibrin fibers. Addition of $20 \mathrm{U} / \mathrm{ml}$ of hirudin to the perfusate diminished this fibrin formation, and when perfusions were performed with $5 \mathrm{U} / \mathrm{ml}$ heparin as anticoagulant the fibrin fibers disappeared, leaving only association of fibrinogen with platelets. Further experiments were therefore carried out with $5 \mathrm{U} / \mathrm{ml}$ heparin as anticoagulant. On electron lucent parts of fully spread platelets that had adhered to matrices of endothelial cells and fibroblasts, fibrinogen often appeared localized at the central region of the platelets (not shown). Binding of fibrinogen on cell bodies of dendritic platelets and the association within larger aggregates could not be analyzed on whole mounts. Occasionally, fibrinogen could be detected on pseudopodes that connect adjacent platelets.

Immunolabeling of $\mathrm{vWf}$ resulted in the accumulation of gold particles in small clusters and sometimes in linear arrays on the endothelial cell matrices. These clusters and linear arrays could also be detected on the surface of spread platelets. From three-dimensional analysis it became apparent that many of these linear arrays of gold particles connect adjacent platelet 

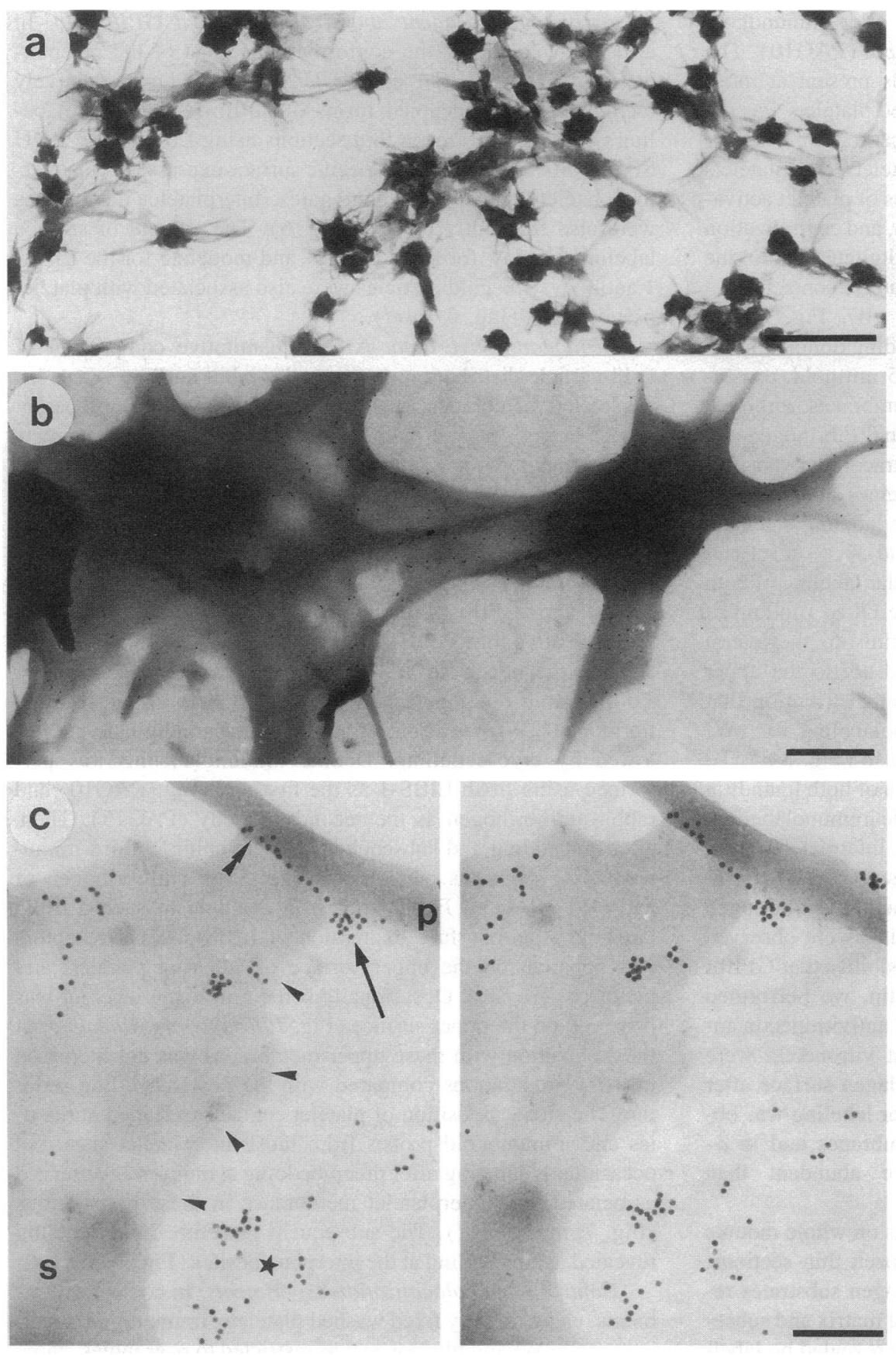

Figure 1. Series of whole mount views of platelet coverage. (a) Low magnification electronmicrograph after 5 min of perfusion over endothelial cell matrix showing dendritic and spread forms of adhered platelets. Aggregate formation occurred only to a low extent. Bar, $5 \mu \mathrm{m}$. (b) High magnification electronmicrograph after immunogold labeling with rabbit polyclonal anti-GPIIb antibody and PAG10. Perfusion for 5 min over endothelial cell matrix. On electron-dense cell bodies and small aggregates surface labeling is not resolved. Immunogold labeling is only visualized at the upper surface of spread extensions and is randomly scattered. Pseudopodal extensions are also labeled. Bar, $500 \mathrm{~nm}$. (c) High magnification stereo-paired electron micrograph. $5 \mathrm{~min}$ of perfusion over endothelial cell matrix. Immunolabeling for $\mathrm{vWf}$ followed by PAG10. Note the presence of clustered gold particles in the matrix (star). The contours of a spread platelet are indicated by small arrowheads. A pseudopod is shown in close apposition with the margin of the adjacent spread platelet. Gold particles associated to the matrix (arrow) extend upwards to the pseudopod and subsequently down to the spread platelet (double arrowhead). Bar, 200 nm. $p$, pseudopod; $s$, spread platelet. membranes. In Fig. $1 c$, the gold particles are attached as a cluster in the endothelial cell matrix (arrow) and extend upwards to a pseudopod of a neighboring platelet and subsequently downwards to the margin of a spread platelet (double arrowhead). Similar findings were obtained when perfusions were performed over fibroblast matrices where no vWf was found in the matrix. Only at or close to sites where platelets adhered to the matrix was vWf immunostaining abundant. After perfusion over type I collagen, large amounts of vWf had bound to the collagen surface (not shown). Incubation of perfused matrices with control antibody and/or protein $\mathrm{A}$-gold alone resulted in very low background staining $\left(0.7\right.$ gold particles $/ \mu \mathrm{m}^{2}$ and 0.3 gold particles $/ \mu \mathrm{m}^{2}$, respectively). Immunolabeling of fibroblast and endothelial cell matrices with anti-vWf antibody before perfusion with whole blood revealed only labeling of the endo- thelial cell matrices ( $>30$ gold particles $/ \mu \mathrm{m}^{2}$ ), indicating that $\mathrm{vWf}$ is already present in this matrix before perfusion; no labeling was found in fibroblast matrices.

\section{Ultra-thin cryosectioning}

General observations. More extensive information about the surface distribution of GPIIb-IIIa and the ligands vWf and fibrinogen was obtained from frozen thin sections of adhered platelets. Immunolabeling was performed on thin frozen sections of platelets adhering to collagen (postembedding) and directly on adhering platelets before embedding and cryosectioning (preembedding labeling). Postembedding labeling on frozen thin sections provided a unique way to study polar events during platelet adhesion and aggregation. A low magnification electronmicrograph of a platelet thrombus formed after perfu- 
sion over type I collagen is shown in Fig. 2 after immunogold double labeling of vWf (PAG5) and fibrinogen (PAG10). The high magnification inset shows both ligands present at interplatelet contacts. The ultrastructure of adhered platelets was not affected by the low hydrofluoric acid concentration used for detaching the melamine foils. Adhered platelets and platelets in aggregates generally showed characteristics of platelet activation, i.e., shape change, pseudopod formation, and centralization of $\alpha$-granules. Pseudopodal extensions interdigitated within the platelet thrombi, thus forming many interplatelet contacts.

Immunolocalization of fibrinogen and $v W f$. Fig. 2 also shows immunogold staining after postembedding double immunolabeling of fibrinogen and vWf (10 and $5 \mathrm{~nm}$ gold, respectively). Label is present at interplatelet membranes, although many platelet contact sites showed no labeling. Fibrinogen and vWf were also abundantly present in large intracellular vacuoles and in $\alpha$-granules. The upper surface membranes of aggregates facing the blood stream had a much lower labeling intensity than the interplatelet membranes (Figs. 2 and 3). Contact and dendritic platelets showed a similar intracellular labeling of both ligands in $\alpha$-granules and in vacuoles of the OCS. Binding of vWf and fibrinogen was also restricted mainly to the lateral membranes of adjacent contact platelets and not to the upper surface (Figs. $3 d$ and 4). The typical linear distribution that we observed in whole mounts after immunolabeling for $\mathrm{vWf}$ was occasionally observed in thin sections also (Fig. $3 b$ ). To extend our findings concerning the association of both ligands at interplatelet membranes, we performed double immunolabeling. vWf and fibrinogen colocalized at the same interplatelet areas and sometimes in large intracellular vacuoles (Fig. $3 d$ ). However, some interplatelet contact sites contained only fibrinogen (Fig. $3 c$ ), while also interplatelet contact sites were observed that lacked both ligands. To exclude the possibility that GPIIbIIIa is occupied by fibronectin or vitronectin, we performed control experiments using antifibronectin and antivitronectin antibodies. Fibronectin and to a lower extent vitronectin were both strongly associated with the type I collagen surface after perfusion. Platelet-associated and intracellular labeling was observed at low densities at interplatelet membranes and in $\alpha$ granules, fibronectin being slightly more abundant than vitronectin (results not shown).

Immunolabeling of matrices. Our findings on whole mounts of fibroblast matrices were confirmed in frozen thin sections. Matrices of endothelial cells and type I collagen substrates revealed vWf labeling. Perfusion over fibroblast matrix and subsequent immunolabeling of $\mathrm{vWf}$ and fibrinogen revealed no labeling at sites in the matrix where no platelets adhered. At the interface between adhered platelets and fibroblast matrix, however, both ligands were found localized in a similar intensity as at interplatelet sites. An example of two contact platelets adhering to a fibroblast matrix is given in Fig. 4 after double immunolabeling of $\mathrm{vWf}$ and fibrinogen. Lateral contacts and basal contacts show labeling of both ligands.

Immunolocalization of GPIIb-IIIa. Immunolocalization of GPIIb-IIIa using a polyclonal anti-GPIIb-IIIa antibody and protein A-gold is shown in Fig. 5. Gold particles were distributed evenly on the upper surface membranes of small aggregates and at interplatelet membranes (Fig. $5 a$ ). Membranes of $\alpha$ granules and of the OCS also exhibited specific GPIIb-IIIa labeling. Membranes of contact and dendritic platelets exhibited a similar extensive GPIIb-IIIa labeling (Fig. 5 b). A similar distribution was obtained when an anti-GPIIIa mAb (C17) or a polyclonal anti-GPIIb antibody was used (not shown).
Activation-dependent and ligand-occupied GPIIb-IIIa. In an attempt to follow the conformational state of the receptor, we used mAbs LIBS-1 and RUU SP 2.41, which selectively recognize ligand-occupied forms of GPIIb-IIIa. Immunolabeling performed on frozen thin sections using LIBS-1 and RUU SP $2.41 \mathrm{mAbs}$ resulted in a specific surface expression on adhering platelets and platelet aggregates. Interplatelet membranes were also frequently labeled (Fig. 6). The amount of surface labeling was low for RUU SP 2.41 and moderate for the LIBS1 antibody. The gold particles were also associated with platelet pseudopodes (Fig. 6, inset).

Semiquantitative data. A semiquantitative comparison of gold particle distribution on upper thrombus surface versus interplatelet membranes is shown in Table III. A significantly higher fibrinogen and vWf concentration is apparent at interplatelet membranes $(P<0.05)$. Of interest, the quantitative data of the GPIIb-IIIa distribution indicated a somewhat higher expression on the upper surface than on interplatelet membranes. The data for the receptor distribution were obtained both after immunolabeling with a polyclonal anti-GPIIb antibody and an anti-GPIlb-IIIa antibody. Quantitative analysis of the LIBS-positive forms of GPIIb-IIIa also showed a higher expression on the upper surface than on interplatelet contact sites. To obtain an optimal surface labeling of both GPIIb-IIIa and fibrinogen/vWf, we also performed preembedding labeling followed by cryosectioning. Double immunolabeling was performed using mAb LIBS-1 as the first antibody (PAG10) and rabbit antifibrinogen as the second antibody (PAG15). Then, after embedding and subsequent cryosectioning, a third immunolabeling step was performed using either antifibrinogen or anti-vWf (PAG5). Fig. 7 shows an example of such a triple labeling. Again surface expression of LIBS-positive receptors was apparent on the upper surface of adhering platelets and platelet aggregates. Occasionally some fibrinogen labeling was observed on the upper surface (Fig. 7, double arrowhead), but the association with these upper membranes was not increased in these preparations compared with the postembedding staining. The close apposition of platelet contacts excluded antibodies and immunogold probes from most interplatelet sites, but occasionally labeling after preembedding staining was observed associated with interplatelet membranes in these preparations (Fig. 7, arrowhead). The subsequent postembedding labeling revealed again labeling at the interplatelet sites (Fig. 7, arrows).

Control immunolocalization experiments. In control experiments, using directly fixed washed platelets, immunogold localization of vWf and fibrinogen was restricted to $\alpha$-granules. None of the ligands were found associated with the plasma membrane. Surface expression was negligible when platelets obtained from blood directly collected into fixative were immunolabeled with LIBS-1 or RUU SP 2.41. The adhesion of platelets under flow conditions was accompanied by surface expression of P-selectin (GMP 140), indicating that membranes of $\alpha$-granules had fused with the platelet plasma membrane and with membranes of the OCS. Expression of P-selectin was observed on the upper surface of thrombi and on single adhering platelets (Fig. 8). Additional evidence for platelet secretion was obtained after immunolabeling for thrombospondin. Intracellular vacuoles of the OCS, and to a lower extent interplatelet contact sites, were labeled with thrombospondin. No surface labeling was observed (Fig. 9). Parallel immunolabeling experiments were also performed for immunolocalization of GPIb. The surface distribution of GPIb was random over all membranes, and no clustering was observed (not shown). 

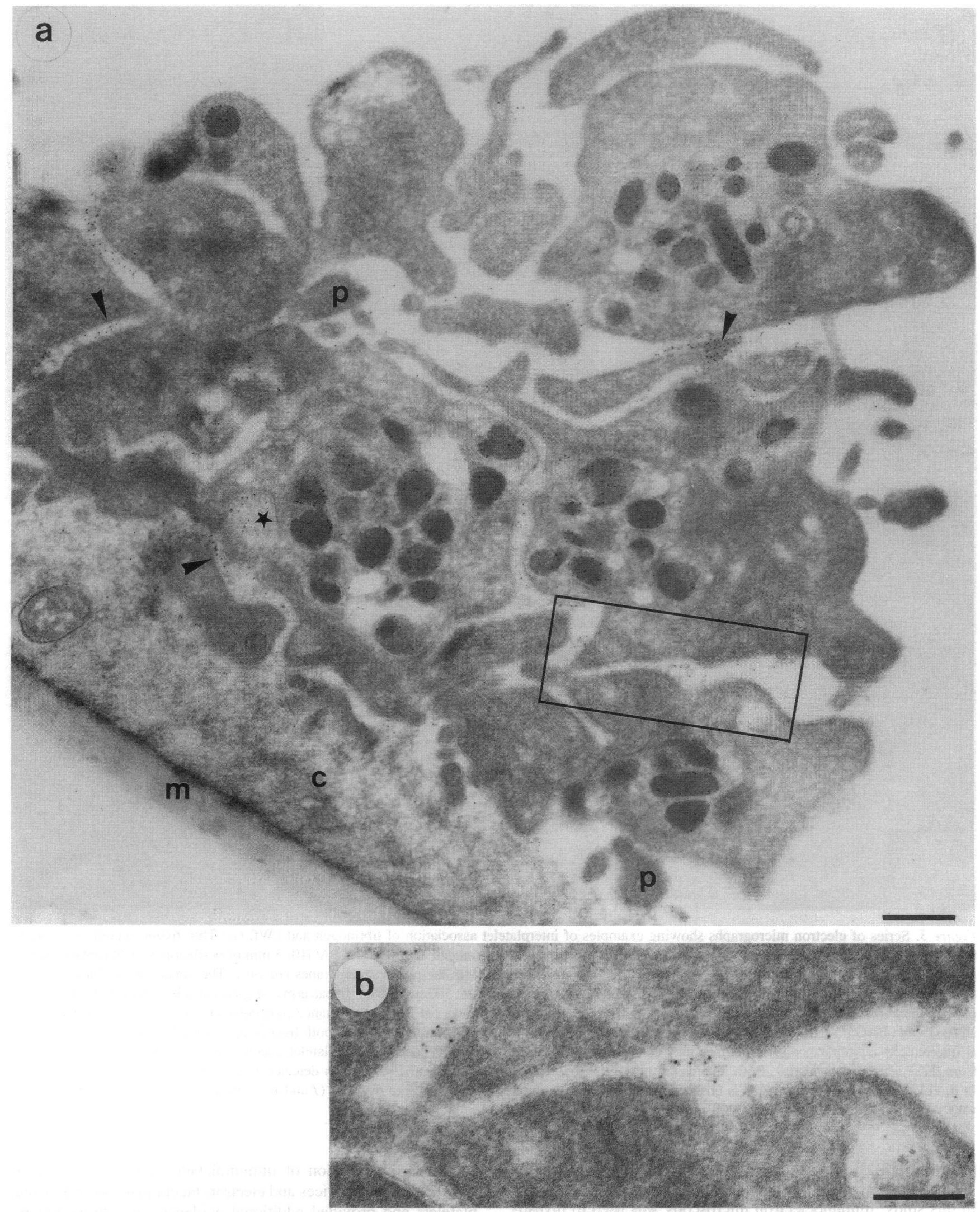

Figure 2. (a) Electronmicrograph of thin frozen section of a small thrombus after $5 \mathrm{~min}$ of perfusion over type I collagen. The platelet ultrastructure is well preserved and reveals typical platelet organelles. Pseudopodes are frequently observed and form many interplatelet contacts. Immunogold double labeling for fibrinogen (PAG10) and vWf (PAG5). Label is predominantly present at interplatelet areas (arrowheads). The OCS (star) and $\alpha$-granules are also labeled. Note the absence of label on the upper surface of the thrombus. Bar, $500 \mathrm{~nm}$. $(b)$ Enlargement of the marked interplatelet area, showing the presence of both ligands. $m$, melamine substrate; $c$, collagen; $p$, pseudopodes. Bar, $250 \mathrm{~nm}$. 


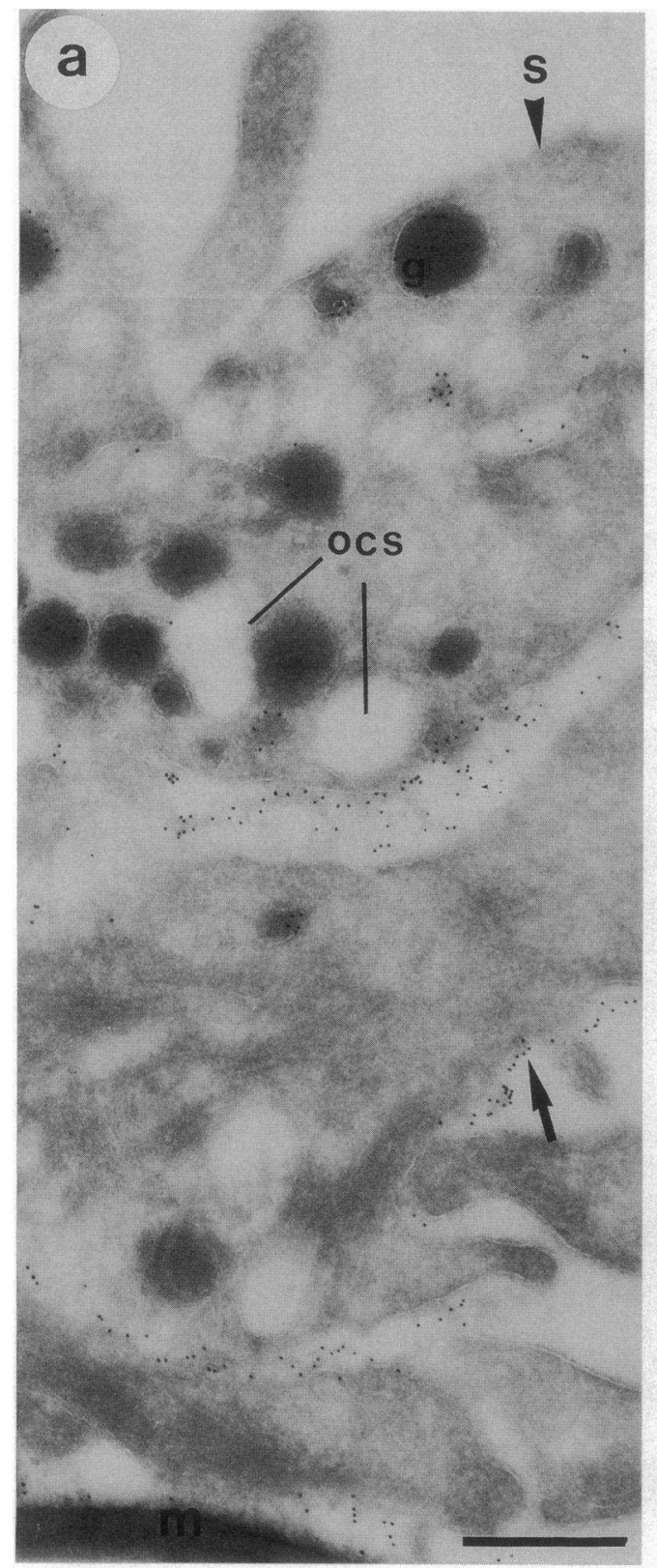

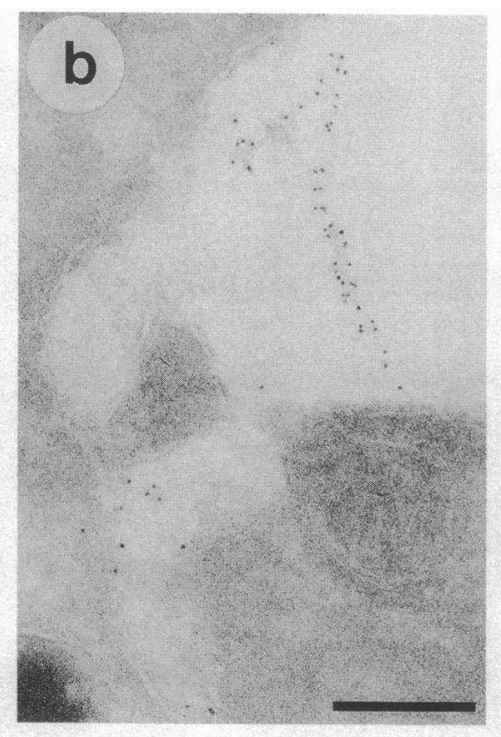

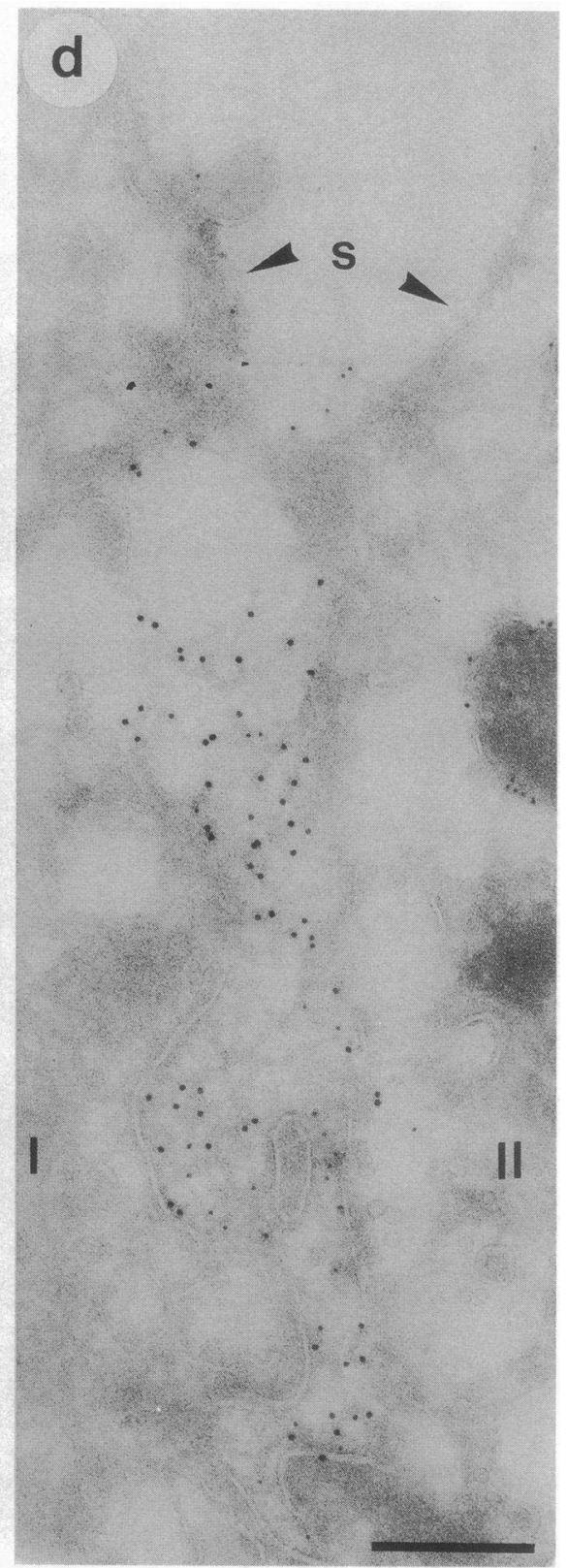

Figure 3. Series of electron micrographs showing examples of interplatelet association of fibrinogen and vWf. (a) Thin frozen section of a small thrombus after immunogold labeling of fibrinogen using a polyclonal antifibrinogen antibody and PAG10. 5 min of perfusion over fibroblast matrix. Many interplatelet contacts show intense labeling. Gold label is associated with the platelet membranes (arrow). The upper surface facing the blood stream $(s)$ is devoid of label. $m$, melamine substrate; $g, \alpha$-granules. Bar, $500 \mathrm{~nm}$. (b) A linear array of gold particles connects two adjacent platelet membranes after immunolabeling of vWf, indicating that vWf multimers act as a long distance molecular bridge. Polyclonal anti-vWf antibody and PAG5. ( $c$ and $d$ ) Double immunogold labeling of vWf and fibrinogen, showing that both ligands are sometimes separately associated at interplatelet membranes and sometimes may colocalize. In $c$, fibrinogen is associated at close platelet contact sites, apparently excluding vWf from these sites (arrowheads). Both ligands are present at the basal interface (arrow). Fibrinogen detected with PAG10 and vWf with PAG15. In $d$, colocalization of both ligands is observed at the lateral membranes of two adhering platelets $(I$ and $I I)$. Fibrinogen detected with PAG5 and vWf with PAG10. $b, c$, and $d$, Bar, $200 \mathrm{~nm}$.

\section{Discussion}

In this study, immunoelectron microscopy was used to investigate the surface distribution of GPIIb-IIIa, and fibrinogen and vWf under flow conditions. Whole mount incubation was followed either by en face evaluation or cross-sectioning. Alternatively, ultra-thin cryosectioning and subsequent immunogold labeling were performed on adhered platelets and small aggregates to study platelet contact events.
En face evaluation of immunolabeled whole mounts was only possible at matrices and electron-lucent margins of adhered platelets and provided additional evidence for a three-dimensional vWf distribution. In thin frozen sections, GPIIb-IIIa appeared evenly distributed on interplatelet membranes and at the upper surfaces of small aggregates. Contact and dendritic platelets showed a similar random GPIIb-IIIa distribution. Our morphological observations suggest that the GPIIb-IIIa complex is not clustered on the platelet surface during initial platelet 


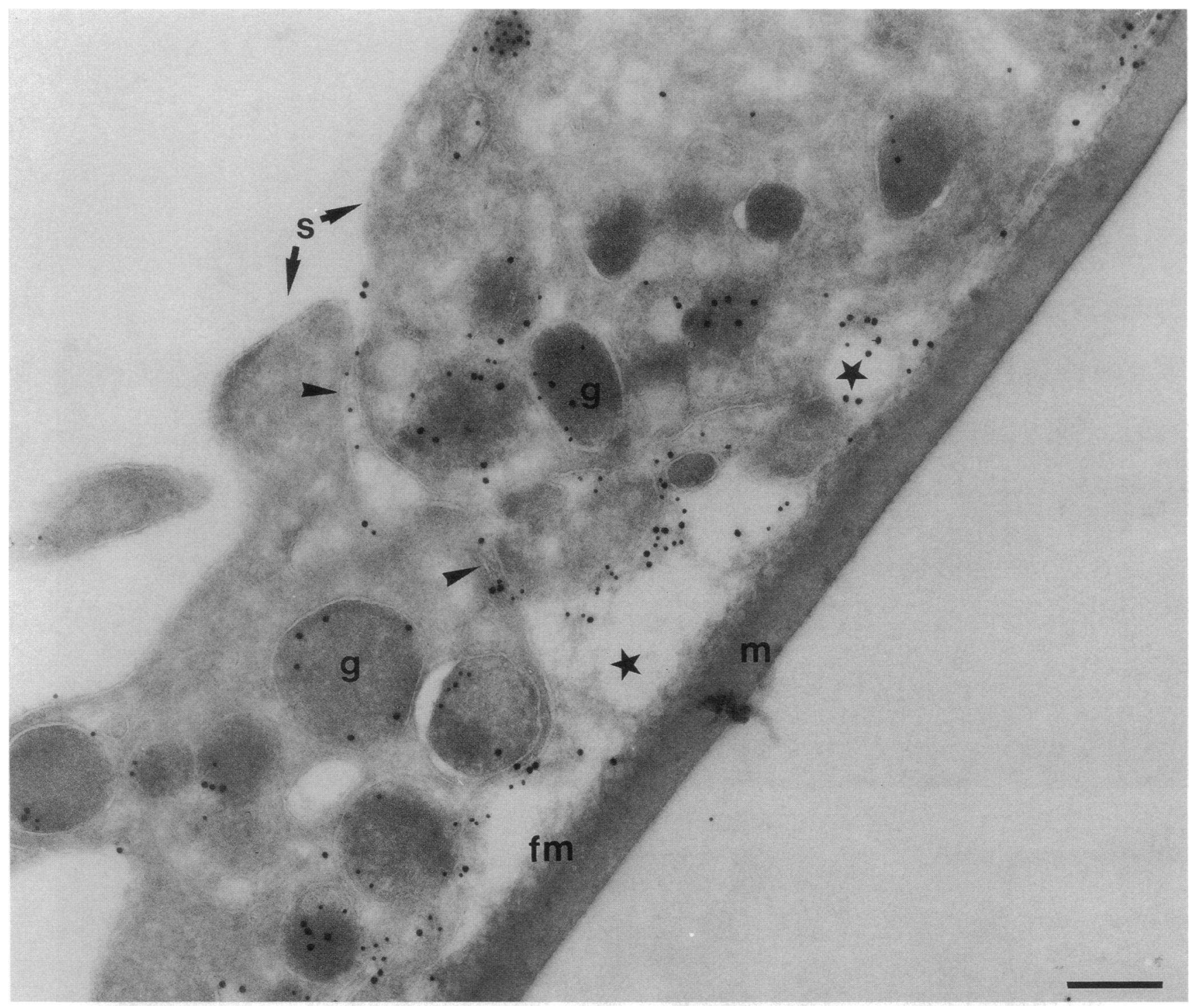

Figure 4. High magnification of two adjacent contact platelets after 5 min of perfusion over fibroblast matrix. vWf detected with PAG10, fibrinogen with PAG15. Both ligands are present at lateral platelet contact sites (arrowheads) and at the basal interface (stars), but not at the platelet surface facing the blood stream $(s) . m$, melamine; $f m$, fibroblast matrix; $g, \alpha$-granule. Bar, $200 \mathrm{~nm}$.

adhesion in flow, but apparently remains evenly distributed over the platelet surface. Moreover, when aggregates were formed in flow, no polarity was observed in the GPIIb-IIIa distribution. Surface activation and stimulation by agonists in general results in centralization of platelet $\alpha$-granules. Simultaneously, released $\alpha$-granule contents may be expressed on the platelet surface. The observed central localization of vWf and fibrinogen that was observed on whole mounts of fully spread platelets may therefore be the result of release of these ligands from $\alpha$-granules during adhesion to the surface. Reorganization of GPIIbIIIa in terms of receptor clustering as described by Isenberg (12) was not observed in our whole mounts. Local redistribution events at sites that are not visualized in whole mounts (i.e., cell bodies of dendritic platelets and interplatelet membranes) are not resolved in thin frozen sections and therefore may still occur.

In agreement with previous studies, we showed that vWf also participates in platelet-platelet interaction under flow conditions. The linear arrays of gold particles that were observed after immunolabeling of vWf probably represent large $\mathrm{vWf}$ multimers that connect adjacent platelets and platelets with matrix. Electron microscopic visualization of vWf substructure with rotary shadowing has shown tangled and extended conformations $(41,42)$. In extended form, the vWf multimers may reach lengths that exceed the diameter of platelets. Since a polyclonal antibody was used in our studies, presumably reacting with several repetitive epitopes, the observed linear gold pattern most likely reflects the extended conformations of vWf. Such extended conformations may form multiple interplatelet contacts via GPIIb-IIIa, thereby reinforcing the platelet-platelet interaction. We also demonstrate colocalization of fibrinogen and vWf at interplatelet contact sites, indicating that both may act as bridging molecules between adjacent platelets. Our ultrastructural results show that large vWf multimers are capable of connecting long interplatelet distances, while in some instances fibrinogen is observed at closer platelet contacts. Whether fibrinogen acts as the short distance molecular bridge and vWf as the long distance molecular bridge, or whether they bind 

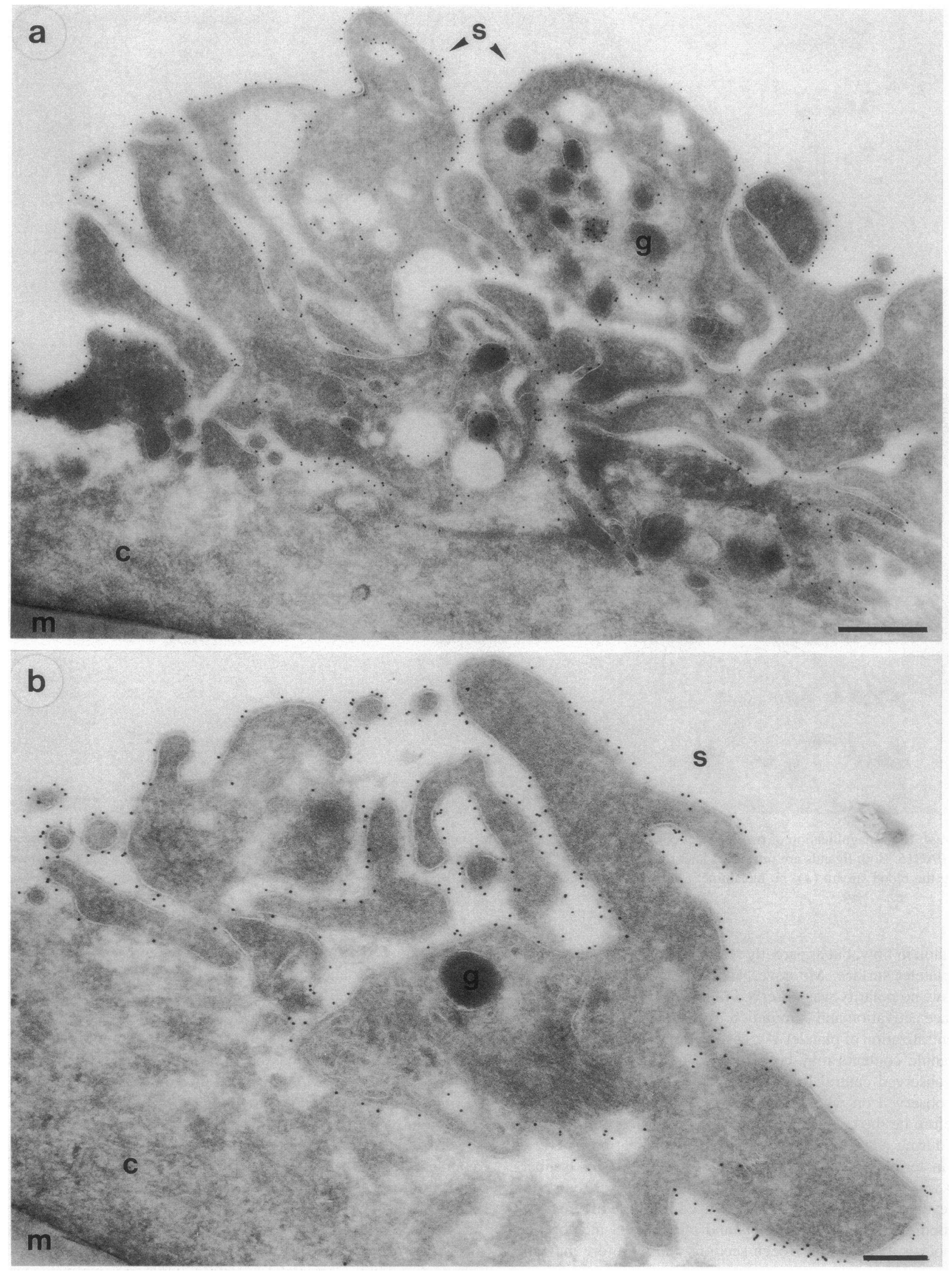

Figure 5. Immunolabeling of GPIIb-IIIa using a polyclonal anti-GPIIb-IIIa antibody followed by PAG10. Perfusion over type I collagen. (a) Part of a thrombus with surface membranes facing the blood stream. Gold particles are associated with lateral interplatelet membranes and upper surface membranes. Membranes of $\alpha$-granules are also labeled. Bar, $500 \mathrm{~nm}$. $(b)$ Immunolocalization of GPIIb-IIIa on dendritic platelet adhering to the collagen surface. Gold particles are evenly distributed over the platelet surface. Note the labeling of pseudopodal extensions. $s$, upper surface; $m$, melamine; $c$, collagen; $g, \alpha$-granule. Bar, $250 \mathrm{~nm}$. 

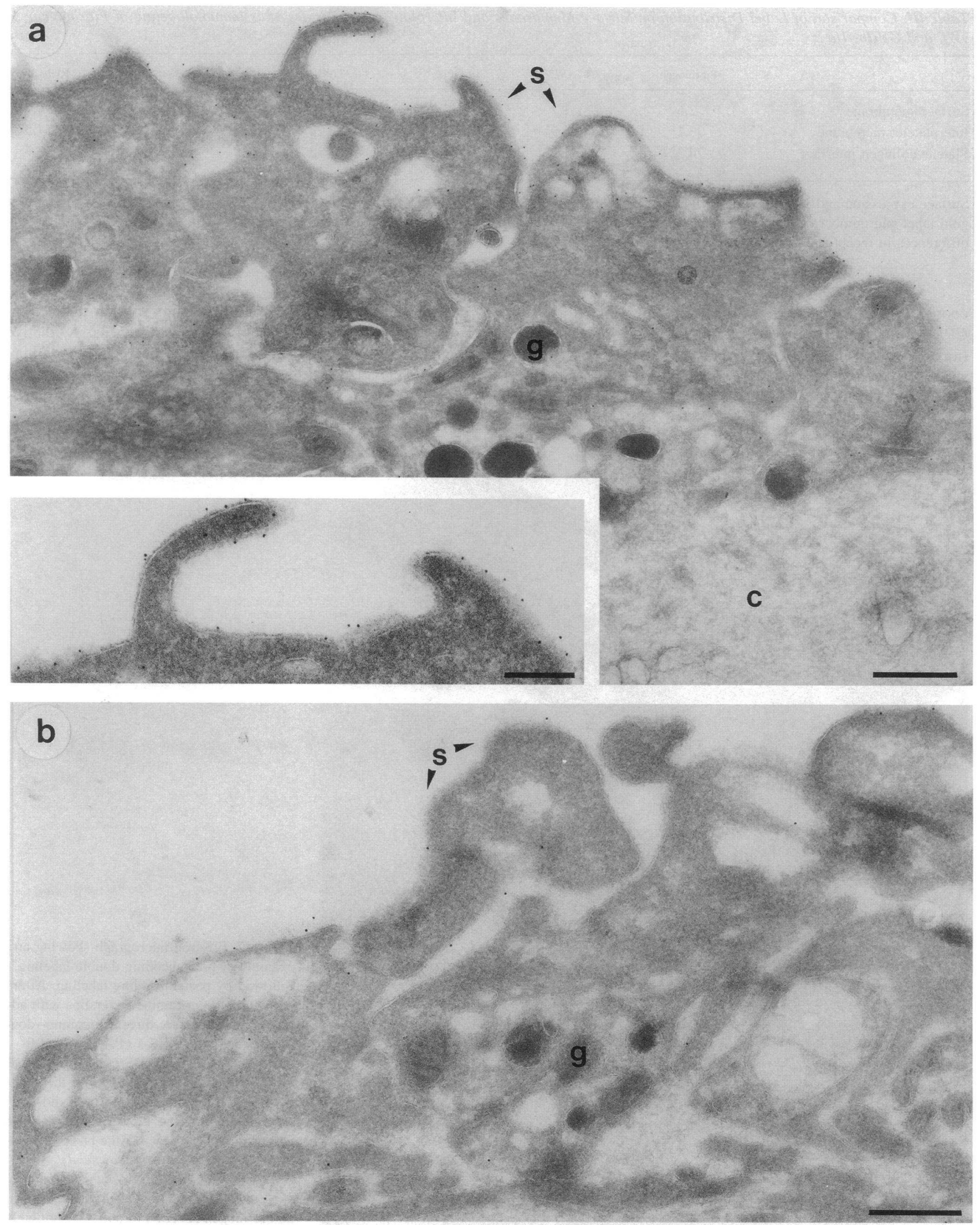

Figure 6. Electron micrographs showing the expression of LIBS-positive forms of GPIIb-IIIa. Perfusion for 5 min over type I collagen. (a) Immunolabeling with anti-LIBS-1 monoclonal antibody, followed by rabbit anti-mouse IgG and PAG10. The upper surface of a small platelet aggregate is clearly labeled. Note the presence of LIBS at a pseudopodial extension (inset) and the absence of LIBS on the $\alpha$-granule membrane. (b) Immunolabeling with RUU SP 2.41 monoclonal antibody, followed by rabbit anti-mouse IgG and PAG10. A similar surface expression is observed, although the amount of label was much less with this antibody. $s$, upper surface; $c$, collagen; $g, \alpha$-granules. $a$ and $b, B a r, 500 \mathrm{~nm} ;$ inset, Bar, $250 \mathrm{~nm}$. 
Table III. Comparison of Label Distribution on Surface Membranes and Interplatelet Membranes after Immunolabeling of Fibrinogen, vWf, and GPIIb-IIIa

\begin{tabular}{lcccccc}
\hline & Fibrinogen & vWf & GPIIb* & GPIIb-IIIa* & LIBS-1* & RUU 2.41* \\
\hline Surface membrane & 2.6 & 1.7 & 40.3 & 56.5 & 54.9 & 44.7 \\
Interplatelet membrane & $23.1^{\ddagger}$ & $6.9^{\ddagger}$ & 33.6 & 24.9 & 29.9 & 31.5 \\
Platelet/collagen interface & 74.3 & 91.5 & 26.1 & 18.7 & 15.2 & 33.7 \\
\hline
\end{tabular}

Surface expression and interplatelet distribution of total GPIIb-IIIa and LIBS-positive forms of the receptor are given. Label density is the ratio of gold label and number of membrane intersections and is expressed as a percentage of the total density. ${ }^{\ddagger}$ Statistically significant. ${ }^{*}$ The large differences in receptor distribution are discussed in the text.

cooperatively, remains unclear. Parker et al. (9) showed that GPIIb-IIIa is an important receptor for platelet vWf, and competition of vWf with fibrinogen for binding to GPIIb-IIIa was shown by Piétu et al. (8). Fibrinogen bridging was visualized by Moon et al. (43), who labeled fibrinogen with heme-octa- peptide. Transmission electron microscopy of their platelet aggregates showed relative small bridging distances. A relative low concentration or even absence of $\mathrm{vWf}$ and fibrinogen may be an explanation for the absence of label at many interplatelet membranes. The sensitivity of the immunogold technique is

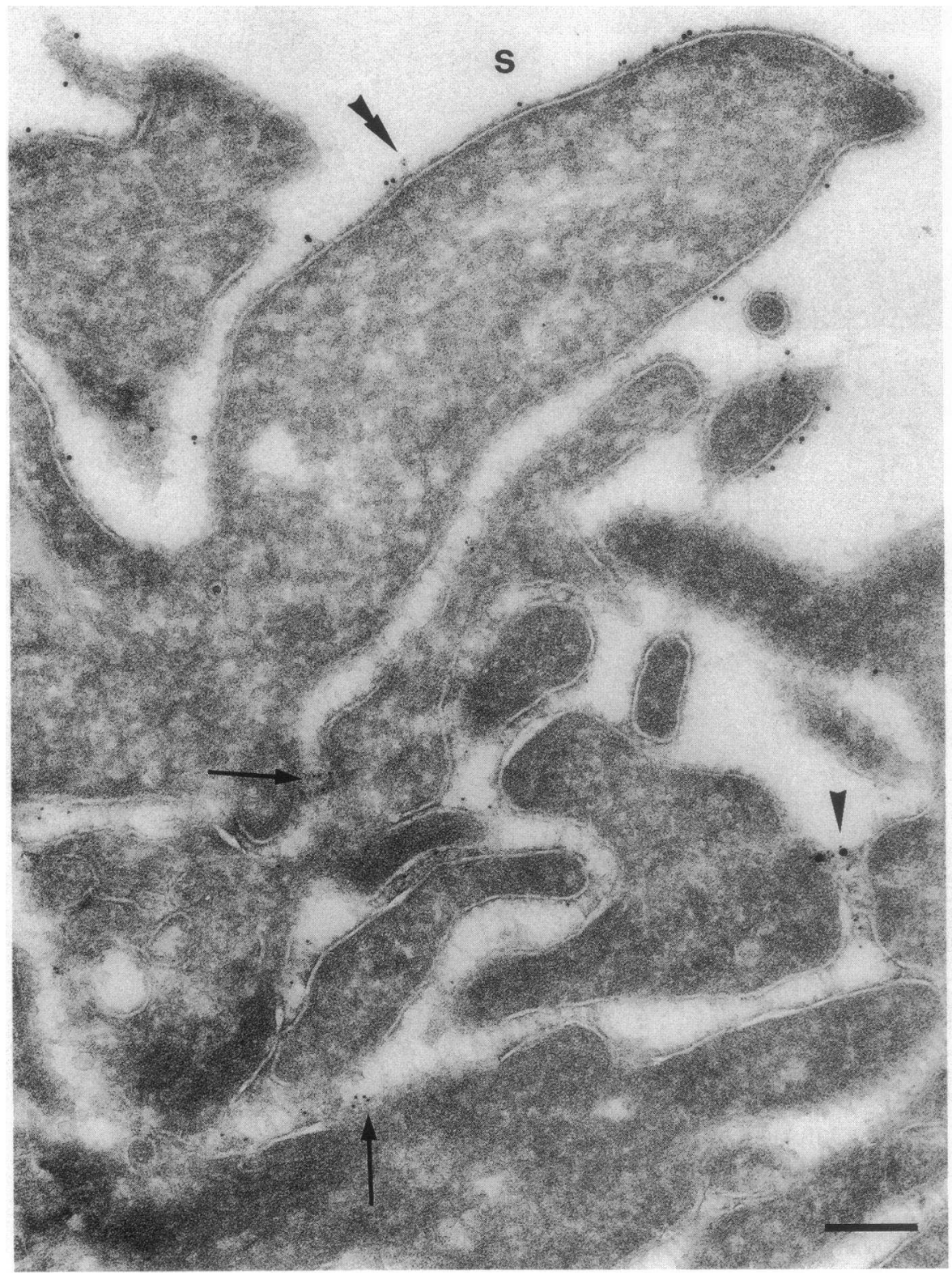

Figure 7. Electron micrograph showing an example of preembedding double labeling, followed by postembedding labeling. After perfusion, the melamine coverslips with adhering platelets were directly immuno-double-labeled with LIBS-1 (PAG10) and fibrinogen (PAG15). LIBS-positive forms of GPIIb-IIIa are again expressed on the surface. This preembedding approach did not substantially improve the surface association and resulted sometimes in the labeling at interplatelet membranes (arrowhead). After cryosectioning, the thin frozen sections were subsequently immunolabeled with either antifibrinogen (PAG5) or anti-vWf antibody (not shown). Interplatelet membranes are again labeled after postembedding labeling (arrows). Occasionally, fibrinogen labeling was observed close to an LIBS epitope ( $d o u$ ble arrowhead). $s$, upper surface. Bar, 200 $\mathrm{nm}$ 


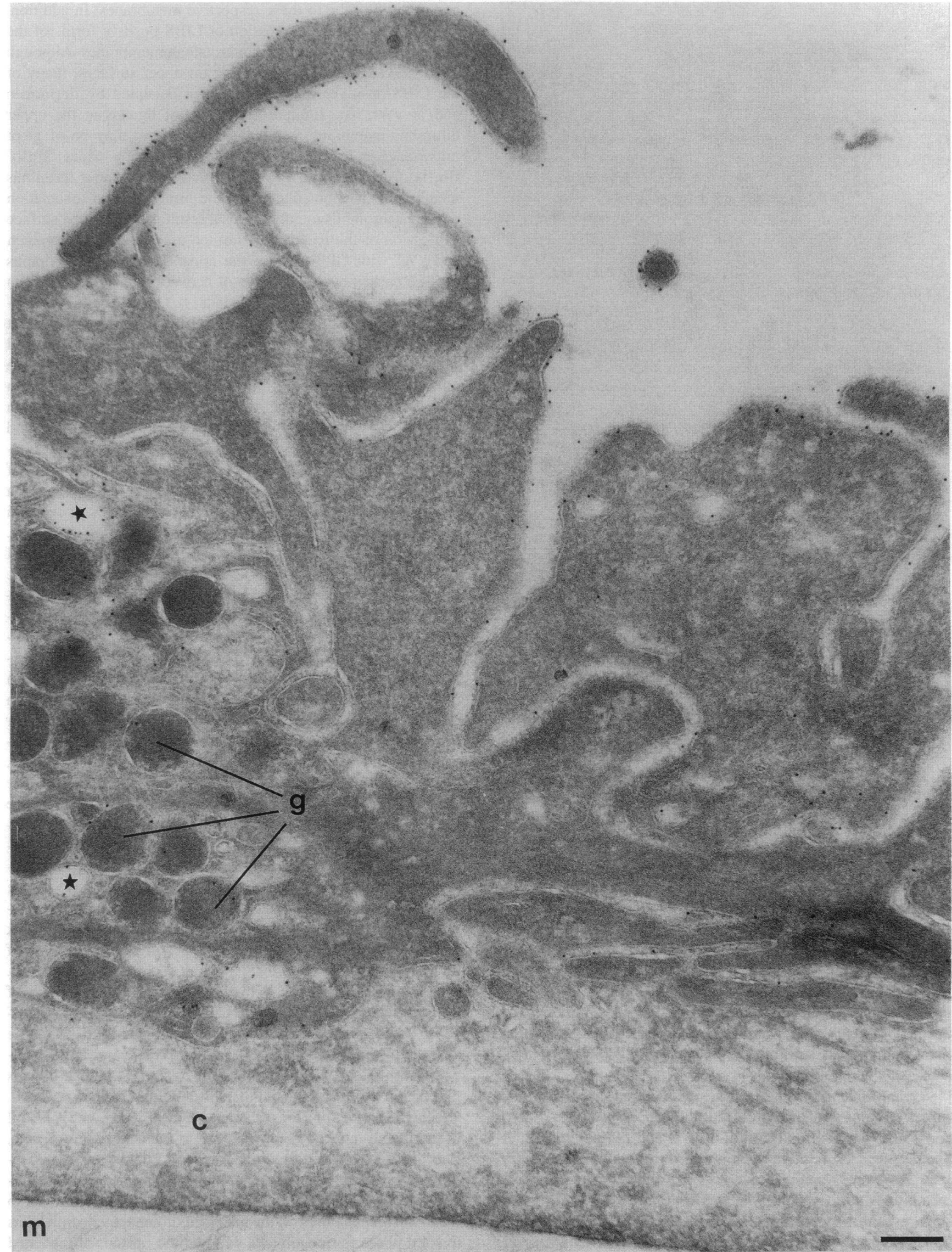

Figure 8. Immunolocalization of P-selectin using a rabbit polyclonal antibody followed by PAG10. 5 min of perfusion over type I collagen. Surface expression of P-selectin is apparent on adhering platelets. Membranes of $\alpha$-granule $(g)$ and the OCS (stars) are also labeled. $m$, melamine; $c$, collagen. Bar, $250 \mathrm{~nm}$. 


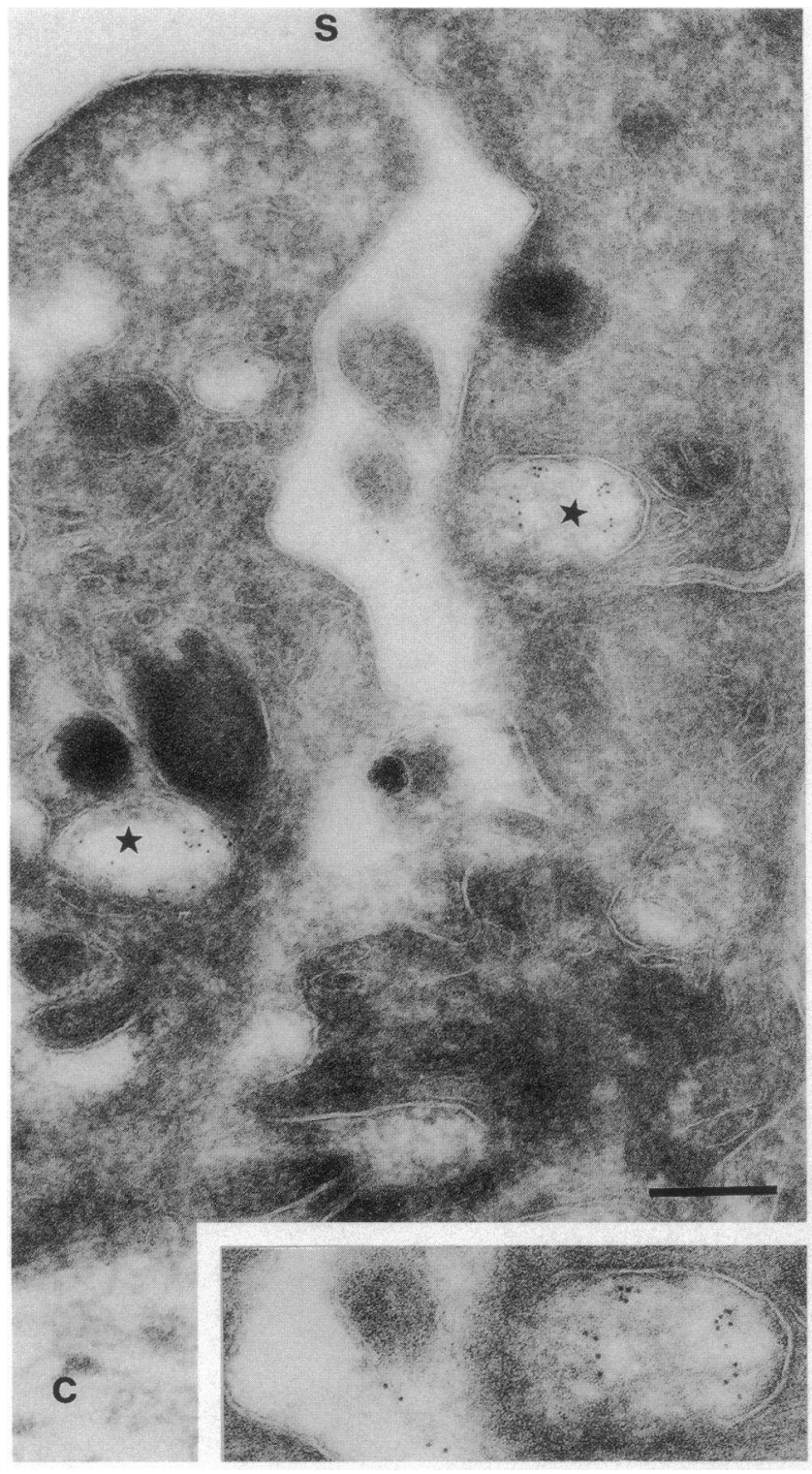

Figure 9. Immunolocalization of thrombospondin on platelets adhering to collagen using a mouse monoclonal antibody and mouse anti-rabbit IgG as intermediate step followed by PAG5. Label is present in large vacuoles of the OCS (stars) and to a lower extent at interplatelet area. Note the apparent release of thrombospondin to the extracellular interplatelet space (inset). $c$, collagen; $s$, upper surface. Bar, $200 \mathrm{~nm}$.

probably not sufficient to detect low concentrations of ligand at many contact sites. Moreover, low concentrations of other ligands may also substitute for vWf and fibrinogen at these sites.

Quantification of the membrane-associated labeling on thin frozen sections of formed thrombi revealed, respectively, a fourand ninefold higher association of vWf and fibrinogen at interplatelet surfaces, relative to the upper thrombus surface. GPIIbIIIa, however, remained distributed evenly over all platelet membranes, with a somewhat higher expression at the upper surfaces. From stereo images of immunogold-labeled cryosections, we know that immunolabel can penetrate to a variable extent into the depth of cryosections. The higher surface labeling of the GPIIb-IIIa receptor compared with interplatelet membranes, therefore, is the result of differential access of antibody and/or gold probe to these respective membranes. In addition, we observed surface expression of LIBS-positive forms of the receptor at upper surface and interplatelet membranes. Although we observed some ligand binding on upper surfaces, many of the LIBS-positive receptors were not occupied by fibrinogen and/or vWf. The limited association of ligands at the upper thrombus membrane facing the bloodstream may be of great importance in the arrest of aggregate formation. Since GPIIbIIIa is distributed evenly on interplatelet and upper thrombus membranes, it is not likely that the limited ligand association on upper thrombus membranes is a result of diminished surface expression of the receptor. A limited association of fibrinogen and vWf with GPIIb-IIIa at the upper surface of a thrombus may be caused by $(a)$ absence of activation of GPIIb-IIIa; $(b)$ specific occupation by other ligands; $(c)$ redistribution of activated GPIIb-IIIa towards platelet-substrate or platelet-platelet contact sites; $(d)$ rapid "closure" of activated GPIIb-IIIa; and $(e)$ reversible ligand binding to activated GPIIb-IIIa. Absence of activated GPIIb-IIIa (a) could occur if platelet activation after adhesion would start at the site of adhesion and from there spread along the platelet membrane. Released ADP and synthesized thromboxane A2, involved as mediators in collagen-induced aggregation, however, will activate other parts of the platelet. In our perfusion model we show surface expression of LIBS-positive GPIIb-IIIa on the upper surfaces of thrombi facing the blood stream, making such an explanation less likely. Binding of fibronectin and vitronectin at the upper surface of adhering platelets $(b)$ was not observed in control experiments. Both ligands appeared associated with the type I collagen surface and were only to a low extent present at interplatelet membranes. Although low concentrations of ligands cannot be detected with this technique, a specific occupation of the LIBSpositive forms of GPIIb-IIIa by fibronectin and/or vitronectin does not seem likely under our flow conditions. Redistribution of ligand associated GPIIb-IIIa (c) may also play a role. Our semiquantitative data suggest that there is no preferential redistribution of LIBS-positive forms at interplatelet membranes, which is not in agreement with this idea. Recent studies have indicated that GPIIb-IIIa activation is a dynamic and reversible process, and closure of activated receptors $(d)$ will occur particularly with weak agonists when no ligand is presented (reference 44 and van Willigen, G., and J. W. N. Akkerman, manuscript submitted for publication). The functional state of the receptor on adhering platelets may be different to the conformation after stimulation with such agonists. Collagen is not a weak agonist, and surface expression of P-selectin and the presence of thrombospondin in OCS indicates that secretion had occurred. Moreover, activation of GPIIb-IIIa occurred in the presence of fibrinogen and vWf. Taken together, these data rule out hypothesis $d$, rapid closure of activated unoccupied GPIIb-IIIa. The absence of fibrinogen and vWf and the presence of LIBS-positive GPIIb-IIIa $(e)$ support a hypothesis suggesting that ligands first bound to GPIIb-IIIa, but that this binding has been reversed. GPIIb-IIIa is then no longer able to bind ligands, but it is still in the ligand-induced conformation. In a recent review article, Lüscher et al. (45) postulated that tight packing of bound fibrinogen may form an adequate adhesive surface for nonactivated circulating platelets. In this context it is of importance to mention recent studies on the adhesion of nonactivated platelets to solid phase fibrinogen $(46,47)$ and the fibrinogen mediated interaction of cells exposing nonactivated GPIIb-IIIa with already existing aggregates (48). In our perfusion model, a minimal number of bound ligand molecules may be required to 
generate such an "adhesive" surface for newly arriving circulating platelets. The relative absence of ligands on the upper surface of adhering platelets or thrombi may thus have important consequences for aggregate formation. The absence of ligands which we observe here has been postulated in literature as a cause for the formation of a single monolayer of platelets when subendothelium was exposed to flowing blood in experimental animals (49). Our observations are in agreement with this.

Lewis et al. (50) also found a discrepancy between localization of GPIIb-IIIa and fibrinogen-gold binding to surface-spread platelets. Similar data were reported by Kieffer et al. (51) who used surface-spread platelets, incubated at $4^{\circ} \mathrm{C}$ with antibodies to GPIIb-IIIa, fibrinogen, and vWf. Heilmann et al. (52) described ubiquitous presence of GPIIb-IIIa and local absence of fibrinogen under aggregating conditions. The experimental design of our present studies, however, is basically different. Our perfusion experiments were designed to study the GPIIbIIIa distribution under flow conditions, whereas the published studies were carried out under static conditions. Secondly, in our perfusion experiments, adhered platelets were fixed before incubation with specific antibodies.

The interaction of vWf with fibrillar type I collagen has been described previously (53). Interaction of fibrinogen with type I collagen, which was observed here, was not expected and may play a role in the platelet-substrate interaction. The origin of fibrinogen and $\mathrm{vWf}$ at the interface of adhered platelets and fibroblast matrix remains unclear. In a perfusion experiment using platelets reconstituted in human albumin solution, we observed vWf and fibrinogen in large vacuoles at close proximity to the basal platelet membrane, suggesting release towards the basal interface (not shown). This local polar release of endogenous fibrinogen and vWf may then contribute to the spreading of the platelet.

In this study we have shown the preferential localization of fibrinogen and vWf between and below platelets, whereas GPIIb-IIIa itself and LIBS-positive forms of the receptor are distributed evenly over all membranes. Therefore we hypothesize that the binding of vWf and fibrinogen to GPIIb-IIIa is reversible on the upper surface of adhering platelets under flow. We believe that the decreased association of fibrinogen and vWf with the upper surface of thrombi may limit thrombus growth under flow conditions. The cause of this phenomenon is still unknown and deserves further investigation.

\section{Acknowledgments}

We wish to thank Dr. Mark Ginsberg for kindly providing the LIBS-1 monoclonal antibody and Dr. Michael C. Berndt for providing the polyclonal anti-GPIIb-IIIa and P-selectin antibodies. The authors are grateful to Maurits K. Niekerk and René Scriwanek for preparing the electronmicrographs.

M. Lozano Molero was supported by a grant from Boehringer Ingelheim S.A.E. (Sociedad Anónima Española) (Barcelona, Spain).

\section{References}

1. Weiss, H. J., H. R. Baumgartner, T. B. Tschopp, V. T. Turrito, and D. Cohen. 1978. Correction by factor VIII of the impaired platelet adhesion to subendothelium in von Willebrands disease. Blood. 51:267-279.

2. Stel, H. V., K. S. Sakariassen, P. G. de Groot, J. A. van Mourik, and J. J. Sixma. 1985. Von Willebrand factor in the vessel wall mediates platelet adherence. Blood. 65:85-90.

3. Baumgartner, H. R., T. B. Tschopp, and D. Meyer. 1980. Shear rate dependent inhibition of platelet adherence and aggregation on collagenous surfaces by antibodies to human factor VIII/von Willebrand factor. Br. J. Haematol. 44:127139.

4. Morgenstern, E., H. J. Reimers, and C. Miyashita. 1984. Ultrastructural studies on the binding sites of fibrinogen on platelet surface during aggregation. Acta Histochem. 29(Suppl.):183-189.

5. Houdijk, W. P. M., P. G. de Groot, P. F. E. M. Nievelstein, K. S. Sakariassen, and J. J. Sixma. 1986. Subendothelial proteins and platelet adhesion: von Willebrand factor and fibronectin, not thrombospondin, are involved in platelet adhesion to extra-cellular matrix of human vascular endothelial cells. Arteriosclerosis. 6:24-33.

6. Coller, B. S., E. I. Peerschke, L. E. Scudder, and C. A. Sullivan. 1983. Studies with a murine monoclonal antibody that abolishes ristocetin induced binding of von Willebrand factor to platelets: additional evidence in support of GPIb as a platelet receptor for von Willebrand factor. Blood. 61:99-110.

7. Weiss, H. J., V. T. Turrito, and H. R. Baumgartner. 1986. Platelet adhesion and thrombus formation on subendothelium in platelets deficient in GPIIb-IIIa, GPIb and storage granules. Blood. 67:322-330.

8. Piétu, G., G. Cherel, G. Marguerie, and D. Meyer. 1984. Inhibition of von Willebrand factor-platelet interaction by fibrinogen. Nature (Lond.). 308:648649.

9. Parker, R. I., and H. R. Gralnick. 1986. Identification of platelet glycoprotein IIb/IIIa as the major binding site for released platelet-von Willebrand factor. Blood. 68:732-736.

10. Plow, E. F., M. D. Pierschbacher, E. Ruoslahti, G. A. Marguerie, and M. H. Ginsberg. 1985. The effect of Arg-Gly-Asp-containing peptides on fibrinogen and von Willebrand factor binding to platelets. Proc. Natl. Acad. Sci. USA. 82:80578061 .

11. Asch, E., and E. Podack. 1990. Vitronectin binds to activated human platelets and plays a role in platelet aggregation. J. Clin. Invest. 85:1372-1378.

12. Isenberg, W. M., R. P. McEver, D. R. Phillips, M. A. Shuman, and D. F. Bainton. 1987. The platelet fibrinogen receptor: an immunogold-surface replica study of agonist-induced ligand binding and receptor clustering. J. Cell Biol. 104:1655-1663.

13. Lewis, J. C., C. Johnson, P. Ramsamooj, and R. R. Hantgan. 1988. Orientation and specificity of fibrin protofibril binding to ADP-stimulated platelets. Blood. 72:1992-2000.

14. Suzuki, H., R. L. Kinlough-Rathbone, M. A. Packham, K. Tanoue, H. Yamazaki, and J. F. Mustard. 1988. Immunocytochemical localization of fibrinogen during thrombin-induced aggregation of washed human platelets. Blood. 71:1310-1320.

15. Phillips, D. R., I. F. Charo, L. V. Parise, and L. A. Fitzgerald. 1988. The platelet membrane glycoprotein IIb-IIIa complex. Blood. 71:831-843.

16. Wencel-Drake, J. D. 1990. Plasma membrane GPIIb/IIIa. Evidence for a cycling receptor pool. Am. J. Pathol. 136:61-70.

17. Isenberg, W. M., R. P. McEver, D. R. Phillips, M. A. Shuman, and D. F. Bainton. 1989. Immunogold-surface replica study of ADP-induced ligand binding and fibrinogen receptor clustering in human platelets. Am. J. Anat. 185:142-148.

18. Hourdillé, P., S. Benabdallah, F. Belloc, and A. T. Nurden. 1985. Distribution of glycoprotein IIb-IIIa complexes in the surface membranes of human platelets and megakaryocytes. Br. J. Haematol. 59:171-182.

19. White, J. G., E. L. Leistikow, and G. Escolar. 1990. Platelet membrane responses to surface and suspension activation. Blood Cells $(N Y)$. 16:43-72.

20. White, J. G. 1990. Induction of patching and reversal on surface-activated human platelets. Br. J. Haematol. 76:108-115.

21. White, J. G. 1990. Separate and combined interactions of fibrinogen-gold and latex with surface-activated platelets. Am. J. Pathol. 137:989-998.

22. Loftus, J. C., and R. M. Albrecht. 1984. Redistribution of the fibrinogen receptor of human platelets after surface activation. J. Cell Biol. 99:822-829.

23. Leistikow, E. A., M. I. Barnhart, G. Escolar, and J. G. White. 1990. Receptor-ligand complexes are cleared to the OCS of surface-activated platelets. Br. J. Haematol. 74:93-100.

24. White, J. G., and G. Escolar. 1990. Fibrinogen receptors do not undergo spontaneous redistribution on surface-activated platelets. Arteriosclerosis. 10:738-744.

25. Sixma, J. J., A. Pronk, P. N. E. M. Nievelstein, J. J. Zwaginga, G. Hindriks, P. Tyburg, J. D. Banga, and P. G. de Groot. 1991. Platelet adhesion to extracellular matrices of cultured cells. Ann. NY Acad. Sci. 614:181-192.

26. Shattil, S. J., J. A. Hoxie, M. Cunningham, and L. F. Brass. 1985. Changes in the platelet membrane GPIIb-IIIa complex during platelet activation. J. Biol. Chem. 260:11107-11114.

27. Coller, B. S. 1985. A new murine monoclonal antibody reports an activation-dependent change in the conformation and/or microenvironment of the platelet glycoprotein Ilb-IIIa complex. J. Clin. Invest. 76:101-108.

28. Woods, V. I., L. E. Wolff, and D. M. Keller. 1986. Resting platelets contain a substantial centrally located pool of glycoprotein IIb-IIIa complex which may be accessible to some but not other extracellular proteins. J. Biol. Chem. 261:15242-15251.

29. Cramer, E. M., G. F. Savidge, W. Vainchencker, M. C. Berndt, D. Pidard, J. P. Caen, J. M. Masse, and J. Breton-Gorius. 1990. Alpha-granule pool of glycoprotein IIb-IIIa in normal and pathological platelets and megakaryocytes. Blood. 75:1220-1227. 
30. Tettero, P. A. T., P. M. Landsdorp, O. C. Leeksma, and A. E. G. von dem Borne. 1983. Monoclonal antibodies against human platelet glycoprotein IIIa. Br. J. Haematol. 55:509-522.

31. Metzelaar, M. J., J. J. Sixma, and H. K. Nieuwenhuis. 1990. Detection of platelet activation using activation specific monoclonal antibodies. Blood Cells (NY). 16:85-96.

32. Frelinger, A. L., I. Cohen, E. F. Plow, M. A. Smith, J. Roberts, S. C.-T. Lam, and M. H. Ginsberg. 1990. Selective inhibition of integrin function by antibodies specific forligand-occupied receptor conformers. J. Biol. Chem. 265:6346-6352.

33. Frelinger, A. L., X. P. Du, E. F. Plow, and M. H. Ginsberg. 1991. Monoclonal antibodies to ligand occupied conformers of integrin $\alpha \mathrm{IIb} \beta 3$ (glycoprotein IIb-IIIa) after receptor affinity. J. Biol. Chem. 266:17106-17111.

34. Bouma, B. N., J. A. van Mourik, S. de Graaf, J. M. Hordijk-Hos, and J. J. Sixma. 1976. Immunological studies on human factor VIII (anti-hemophilic factor A, AHF) components produced by low ionic strength dialysis. Blood. 71:253264.

35. Westphal, C., H. Horler, S. Pentz, and D. Frosch. 1988. A new method for cell culture on an electron-transparent melamine foil suitable for successive LM, TEM and SEM studies of whole cells. J. Microsc. (Oxf.). 150:225-231.

36. Houdijk, W. P. M., P. G. de Groot, P. F. E. M. Nievelstein, and J. J. Sixma. 1985. Role of von Willebrand factor and fibronectin in the interaction of platelets in flowing blood with monomeric and fibrillar collagen types I and III. J. Clin. Invest. 75:531-540.

37. Sakariassen, K. S., P. A. M. M. Aarts, P. G. de Groot, W. P. M. Houdijk, and J. J. Sixma. 1983. A perfusion chamber developed to investigate platelet interaction in flowing blood with human vessel wall cells, their extracellular matrix, and purified components. J. Lab. Clin. Med. 102:522-535.

38. Muggli, R., H. R. Baumgartner, T. B. Tschopp, and H. Keller. 1980. Automated assay as a measure for platelet adhesion and aggregation on collagencoated slides under controlled flow conditions. J. Lab. Clin. Med. 95:195-207.

39. Slot, J. W., and H. J. Geuze. 1985. A new method of preparing gold probes for multiple-labeling cytochemistry. Eur. J. Cell Biol. 38:87-93.

40. Slot, J. W., J. J. Geuze, and A. J. Weerkamp. 1988. Localization of macromolecular components by application of the immunogold technique on cryosectioned bacteria. In Methods in Microbiology. Electron Microscopy in Microbiology. Academic Press, New York. 20:11-236.

41. Fowler, W. E., L. J. Fretto, K. K. Hamilton, H. P. Erickson, and P. A. McKee. 1985. Substructure of human von Willebrand factor. J. Clin. Invest. 76:1491-1500.
42. Heijnen, H. F. G., J. Koedam, H. Sandberg, N. Beeser-Visser, J. W. Slot, and J. J. Sixma. 1990. Characterization of FVIII and interaction with von Willebrand factor. An electron microscopic study. Eur. J. Biochem. 194:491-498.

43. Moon, D. G., J. R. Shainoff, and S. R. Gonda. 1990. Electron microscopy of platelet interactions with heme-octapeptide-labeled fibrinogen. Am. J. Physiol. 259:611-618.

44. van Willigen, G., and J. W. N. Akkerman. 1991. Protein kinase C and cyclic AMP regulate reversible exposure of binding sites for fibrinogen on the glycoprotein IIb/IIIa complex of human platelets. Biochem. J. 273:115-120.

45. Luischer, E. F., and S. Weber. 1993. The formation of the haemostatic plug: a special case of platelet aggregation. An experiment and a survey of the literature. Thromb. Haemostasis. 70:234-237.

46. Coller, B. S. 1980. Interaction of normal, thrombasthenic and BernhardSoulier platelets with immobilized fibrinogen: defective platelet-fibrinogen interaction in thrombasthenia. Blood. 55:169-178.

47. Savage, B., and Z. M. Ruggeri. 1991. Selective recognition of adhesive sites in surface-bound fibrinogen by glycoprotein IIb-IIIa on non-activated platelets. J. Biol. Chem. 266:11227-11233.

48. Gawaz, M. P., J. C. Loftus, M. L. Bajt, M. M. Frojmovic, E. F. Plow, and M. H. Ginsberg. 1991. Ligand bridging mediates integrin $\alpha_{\mathrm{mb}} \beta_{3}$ (platelet GPIIB-IIIA) dependent homotypic and heterotypic cell-cell interactions. J. Clin. Invest. 88:1128-1134.

49. Kinlough-Rathbone, R. L., M. A. Packham, and J. F. Mustard. 1983 Vessel injury, platelet adherence and platelet survival. Arteriosclerosis. 3:529546

50. Lewis, J. C., R. R. Hantgan, S. C. Stevenson, T. Thornburg, N. Kieffer, J. Guichard, and J. Breton-Gorius. 1990. Fibrinogen and glycoprotein IIb/IIIa localization during platelet adhesion: localization to the granulomere and at sites of platelet interaction. Am. J. Pathol. 136:239-252.

51. Kieffer, N., J. Guichard, and J. Breton-Gorius. 1992. Dynamic redistribution of major platelet surface receptors after contact-induced platelet activation and spreading: an immunoelectron microscopy study. Am. J. Pathol. 140:57-72.

52. Heilmann, E., P. Hourdillé, A. Pruvost, A. Paponneau, and A. T. Nurden. 1991. Thrombin induced platelet aggregates have a dynamic structure: time-dependent redistribution of glycoprotein IIb-IIIa complexes and secreted adhesive proteins. Arteriosclerosis. 11:704-718.

53. Pareti, F. I., K. Niiya, J. M. McPherson, and Z. M. Ruggeri. 1987. Isolation and characterization of two domains of human von Willebrand factor that interact with fibrillar collagen types I and III. J. Biol. Chem. 262:13835-13841. 